\title{
Perspectives on gender inclusion at work: case of a British police service.
}

\begin{abstract}
Policing is labelled as a 'gendered' occupation (Davies and Thomas, 2008; Westmarland, 2001) and its gendered organisational practices work to the disadvantage of women (Martin and Jurik, 2006). This paper explores employee perspectives on gender diversity and inclusion in the London Metropolitan Police Service (MPS). The empirical evidence in this research shows that employees perceive the work systems and processes in the MPS as favouring the masculine police archetype. Female officers are generally confined to the boundaries of femininity but at the same time they are expected to behave like a 'model employee', which involves assimilating the masculine police archetype. The experiences of most female respondents depict the gendered division of labour (Davies and Thomas, 2008; Westmarland, 2001) that is linked to the business case, and which underpins the access-andlegitimacy perspective on workforce diversity (Dass and Parker, 1999; Ely and Thomas, 2001). Implications for practice and future research are considered.
\end{abstract}

\section{Keywords:}

Gender; diversity perspectives; police

\section{Introduction}

The demographics of policing in remain a predominantly white, heterosexual, maledominated occupation (Heidensohn 1992; Walklate 2000; Brown 2007). Women have encountered considerable difficulty not only in gaining acceptance within the police service but also in dealing with discriminatory promotion practices and sexual banter. Research has 
shown how the 'cult of masculinity' has encouraged discrimination and various forms of sexual harassment against women (Brown, 1998; Heidensohn, 1992; Martin, 1990). The 'macho' and sexualized nature of the jokes and banter affirm male dominance within the organization (Brown, 1992; Fletcher, 1996). This form of social relation operates to exclude women and to discourage them from working in specialist departments such as Criminal Investigation Department (CID) and Traffic (Balkin, 1986; Flynn, 1982; Young, 1991). Brown (1998) investigated the experience of sexual harassment among 1802 policewomen and civilian female staff, and found that 65 per cent of the women had 'heard comments about their own physical appearance'. Plainly, this experience was extremely common although not universal among women in the research sample.

Malcolm Young (1991: 193) observed that policemen were overtly and consistently hostile towards women in 'the job'. His study showed that some women were briefly tolerated as 'honorary men', but they still maintained a low status on the pecking order. These discriminatory experiences of female police officers persisted throughout the years (Fielding and Fielding, 1992; Leishman, Loveday and Savage, 2000; Westmarland, 2001; Davies and Thomas, 2008; Loftus, 2009). Studies have shown that the 'cult of masculinity' (Smith and Gray, 1985) and the taken-for-granted masculine culture of the police service continues to marginalise women. The work culture promotes ‘crime fighting as men's work and social service as women's work' (Fielding, 1994, p. 61). This is owing to the emphasis on physical strength and the perception that women are best suited for emotional labour (Fielding and Fielding, 1992). Female officers are therefore deployed to tasks that are stereotyped as 'female tasks', such as dealing with children, domestic violence, victims of sexual crime, or welfare office-based tasks (Brown, 1998; Brown et al., 1993). Female officers find themselves in uncertain positions regarding their careers as they are encouraged to take on 'specialist' roles in departments dealing with supposedly gendered issues. 
Loftus (2009) found that women faced prejudice in the CID, which is seen as entailing tasks of 'real policing' and so more suitable for the traditional white, male police officer. The masculine police culture marginalises women and thereby limits their policing practice and their prospects for promotion (Morash and Greene, 1986). Ridgeway and Correll (2004) argue that when women enter a particular field and that field is seen to become feminised, it subsequently becomes devalued. Therefore, those who choose to pursue 'appropriate feminine roles' might well be limiting their career prospects because feminine roles are associated with lower performance values or 'recipe knowledge' (Dick and Jankowicz, 2001).

Policing is labelled as a 'gendered' occupation (Davies and Thomas, 2008; Westmarland, 2001) and research shows that its gendered organisational practices work to the disadvantage of women (Martin and Jurik, 2006). The work hours, in particular, are not viewed as family-friendly. Studies on burnout among police officers have shown that female officers tend to experience higher levels of work-related stress (Berg et al., 2003; He et al., 2002). The distressing work schedule is coupled with the expectation to partake in off-duty drinking and after-hours socialising, which are important and prevailing aspects of the police culture that influence group cohesion.

Female officers experience intense pressure to 'prove themselves' and, in doing so, they sometimes adopt the characteristics of the prevailing masculine police culture so as to avoid differential treatment from their male colleagues (Martin, 1980; Young, 1991; Heidensohn, 1992). Research suggests that female officers do not necessarily resist the apparently 'masculine' culture, but, like men, emphasise the importance of physical strength and crime fighting (Heidensohn, 1992).

Westmarland (2001) criticises the notion of genitalia being the definitive sign of masculinity or femininity and questions the ambiguous career positionings simply based on 
gender. Interestingly, some female LGBT officers identified an advantage of their sexual orientation as being able to minimise the disadvantage of gender hierarchy in the police service. Research shows that these individuals are able to 'undo gender' (Chan et al., 2010; Deutsch 2007) because they are not as confined to the boundaries of femininity as heterosexual women are. Some LGBT officers are therefore able to assimilate the masculine police archetype without threatening the masculinity of police officers to the extent that heterosexual women do (Miller, Forest and Jurik, 2003: 376). Nevertheless, Miller et al. (2003) reported that all of the "out" and "closeted" gay/lesbian officers in their study indicated that they had heard or been the target of antigay or lesbian jokes or derogatory slang. Similarly, Colvin (2009) found that the majority of the lesbian/gay officers in the police service said that they experienced social isolation, "outsiderism," and were subjected to homophobic verbal abuse. This is owing to the ethos of a heterosexual masculinity which establishes boundaries between themselves and LGBT officers through social exclusion or verbal intimidation (Belkin and McNichol, 2002; Burke 1993; Colvin, 2009; Lyons et al., 2008; Miller et al., 2003). The potential for challenging this prejudiced behaviour remains a concern among researchers and practitioners alike.

The police is under enormous pressure to find new ways for managing issues around workforce diversity (Loftus, 2008; Holdaway, 1997). Contemporary generations of police are expected to improve the way the police interact with their diverse colleagues as well as with the public. However, policing values and practices are rooted in a professional and organisational identity. The experiences of females, LGBT and BME officers therefore hinge on the rigidity and/or resilience of police occupational culture. 


\section{Methodology}

In order to understand the dynamics of gender diversity and inclusion, this research adopts critical methodological pluralism by incorporating a careful mix of deductive and inductive approaches. Following a principles of abduction, theory acts as an integral part of the methodology instead of being subordinate to the empirical findings. The divisions of the theoretical part of scientific work from the more practical and empirical methodological aspects can jeopardise the sometimes difficult but necessary effort to link empirical research with theorising (Danermark, 2002). Research that adopts an 'either-or' attitude may result in empirical descriptions lacking in theory. In this study, method and theory are not treated as two separate entities of social inquiry; theory is viewed as an inherent and vital part of the research method.

Some diversity researchers are of the view that methodological pluralism is more conducive to studying deeper structures of power and diversity when compared with purist methodologies of positivist or interpretivist tradition (e.g., Özbilgin et al. 2010). This research adopts a pragmatic mixed-methods approach that draws on multiple data sources for making careful abductive inferences.

Data for this study is gathered with an aim to access the in-depth perspectives of the actors and agents of workforce diversity. In an attempt to preserve the richness of the qualitative data, detailed empirical descriptions are presented. Alongside the detailed empirical descriptions, this paper employs abductive reasoning by drawing on other theoretical perspectives and secondary data in order to critically analyse the relationship between the identified perspectives, structures and mechanisms of diversity and inclusion in the MPS.

Stratified sampling was used in order to account for various diversity strands of the workforce. The research sample includes 85 subjects from a variety of races, ranks, a range of 
ages and lengths of service, and mix of genders. This ensured that the study did not focus on the perspectives of only female officers; the perspectives of male officers were also important for carrying out a comprehensive evaluation of the underlying mechanism of workforce diversity.

\begin{tabular}{|l|l|l|}
\hline Gender & $\begin{array}{l}\text { Number of } \\
\text { participants }\end{array}$ & $\mathbf{\%}$ \\
\hline Male & 46 & $54 \%$ \\
\hline Female & 39 & $46 \%$ \\
\hline & & \\
\hline Total & $\mathbf{8 5}$ & \\
\hline
\end{tabular}

Table 1 - Gender profile of interview respondents

\begin{tabular}{|l|l|}
\hline Age range & $\begin{array}{l}\text { Number of } \\
\text { participants } \\
13\end{array}$ \\
\hline $20-29$ & 23 \\
\hline $30-39$ & 38 \\
\hline $40-49$ & 11 \\
\hline $50-59$ & \\
\hline
\end{tabular}

Table 2 - Age profile of interview respondents

The research aimed to achieve a representative sample in terms of age range. The gender mix does not match the current makeup of the MPS workforce but this sample was intentionally sought by the researcher with the aim of accessing a balanced number of genders for comparative analysis of their perspectives on workforce diversity.

\begin{tabular}{|l|l|}
\hline Racio-ethnicity & $\begin{array}{l}\text { Number of } \\
\text { participants }\end{array}$ \\
\hline White British & 54 \\
\hline White Other & 8 \\
\hline Asian & 7 \\
\hline Indian & 2 \\
\hline Black British & 7 \\
\hline Black African & 4 \\
\hline Mixed Other & 3 \\
\hline
\end{tabular}

Table 5.7 - Racio-ethnic profile of interview respondents 
The majority of the participants were white British. The police boroughs endeavoured to schedule interview participants based on their availability during the weeks of data collection in the respective boroughs. Although the research was in favour of accessing a larger number of BME participants, this sample gave a more realistic proportional representation of the MPS's workforce diversity.

\begin{tabular}{|l|l|}
\hline Length of Service & $\begin{array}{l}\text { Number of } \\
\text { participants }\end{array}$ \\
\hline & \\
\hline 3-11 Months & 1 \\
\hline 1-2 years & 4 \\
\hline 3-5 years & 14 \\
\hline 6-9 years & 18 \\
\hline 10-15 years & 9 \\
\hline 16-20 & 15 \\
\hline $21-30$ years & 21 \\
\hline $31-37$ & 4 \\
\hline
\end{tabular}

Table 5.8 - Profile of interview respondents' length of service

The research achieved a fairly representative spread in the 'length of service' of the interview participants. The mass of participants served between 3-30 years in the MPS.

\begin{tabular}{|l|l|}
\hline Rank & $\begin{array}{l}\text { Number of } \\
\text { participants }\end{array}$ \\
\hline & \\
\hline Chief Superintendent & 5 \\
\hline Superintendent & 2 \\
\hline Chief Inspector & 6 \\
\hline Inspector & 9 \\
\hline Sergeant & 15 \\
\hline PC & 26 \\
\hline PCSO & 9 \\
\hline Staff A & 2 \\
\hline Staff B & 4 \\
\hline Staff C & 5 \\
\hline Staff D & 2 \\
\hline
\end{tabular}

Table 5.9 - Rank profile of interview respondents 
The interview participants were not asked to state their sexual orientation but during the discussions, four of the respondents stated that they were lesbians. Although disability was discussed with some respondents, none of the participants identified themselves as disabled.

The coding procedure developed by Strauss and Corbin (1990) was utilised with an aim to preserve the richness and meaning of the qualitative data. This involved reducing and abstracting the empirical data through open, axial and selective coding. The interpretations were refined using abductive reasoning to derive explanations for the diversity perspectives based on the causal powers of various structures and mechanisms identified within the organisation. Multiple data sources were employed for comparative analysis of key variables and relationships. This allowed the researcher to systematically explore multiple layers of the phenomena in order to abduce plausible explanations.

\section{Findings}

A torrent of gender issues poured out during the interview discussions about diversity and inclusion. Many of the female respondents spoke about the challenges they faced in gaining acceptance and respect in a male dominated profession (Smith and Gray, 1985; Davies and Thomas, 2008; Westmarland, 2001). The respondents spoke about a generally positive and inclusive environment but went on to highlight issues that were specific to their particular role in the police service. A female Chief Inspector pointed out that there was only one male subordinate on her team who struggled to take orders from her because of her gender:

"The work environment is pretty good here. There is only one issue with diversity that perhaps affects my work and it comes from a Muslim officer on my team. He doesn't seem to like the idea of answering to a female superior. I get it, it's his cultural background. All the other male officers don't seem to have a problem taking orders from me. Anyway, he still has to respect my rank but I guess the gender issue does make it a bit uncomfortable at times."(Met025 - female, 43, White British) 
A young female officer identified the "macho" style and hierarchical nature of the police as the main hindrance for her integration as a new recruit:

“There are people who will act as if they are superior to you because they've had more time in the job. You'd be in a car and they won't even talk to you, perhaps thinking "you are the new one, you need to prove yourself to me". I wasn't a fan of this macho territorial style; women are more nurturing in this respect. You have to do all the work to prove yourself. It's already a difficult job, you learn while you are on the job but when you have idiots on your team who refuse to support you at the beginning, then you will make errors and those mistakes will escalate because the team will start forming their opinion of you - she's crap or he's crap." (Met071, female, 23, Mixed Other)

Met071 has been in the MPS for only one year. Other respondents (male and female) also highlighted the typical initiation rite of being "thrown in the deep end" so that the team could assess their capabilities (Martin, 1980; Young, 1991; Heidensohn, 1992). This respondent expressed dislike for what she perceived as masculine attitudes and expressed that this was her main difficulty in working with officers on the response teams. It is important to note that this respondent is a Designated Detention Officer (DDO), which is a civilian staff role and so she does not have the same powers as a warranted police constable. Therefore, her experience might have very little to do with her newness, gender or race and more to do with the power relations between police officers and police civilian staff (see also Loftus, 2008; Loveday, 2007).

Female respondents who had longer service and were warranted police officers also spoke about the difficulties they faced in working in a system that was developed in a masculine framework (Davies and Thomas, 2008; Westmarland, 2001; Martin and Jurik, 2006). One female police officer spoke about the insensitive treatment she received while she was pregnant:

"I got pregnant with my first child when I was on TSG [Territorial Support Group] and my governor said to me "don't even think consider coming back part-time; we 
don't want part-timers on TSG. To be told something like that when you are 8.5 months pregnant and about to go off on maternity leave! Well, it implies that you have a choice of either coming back full-time and working the same hours as the team or don't bother coming back love. That's not nice. But I think things have moved on. I can't speak for women now because I'm not pregnant now." (Met048 - female, 34, White British)

Another female officer who recently returned from maternity leave spoke about the level of pressure that is placed on female officers as opposed to female civilian staff:

"Police staff gets 9 months maternity leave, while police officers get 3 months leave, that's discrimination right there. Basically, women in purely administrative roles are treated with more compassion. I guess we [female police officers] are expected to be tougher. I came back after 3 months maternity leave; having given birth to premature twins. I knew I couldn't take any extra time off if I wanted to prove my worth to the team. There is a negative stereotype of females who leave the team to have kids and I wanted to prove that I wasn't one. I had to make it clear that not because I'm a mom meant that I would be less of an officer.” (Met059 - female, 37, White British)

This officer conformed to the three months maternity leave policy and returned to full-time work in order to avoid getting a bad reputation on her team. Martin and Jurik (2006) argue that police organisational policies and practices have gendered police work to the disadvantage of women. The interview respondents express their disapproval of not only the maternity policy but also criticised the police work schedule for being "devastating to family life because of its odd work hours" (Met034). Studies on burnout among police officers have shown that female officers tend to experience higher levels of work-related stress (Berg et al., 2003; He et al., 2002).

Work-related pressures apparently stretched beyond organisational policies and practices as the interview respondents revealed social pressures that were experienced. Females said that they were constrained by their gender and had to 'prove themselves' by adopting a certain mode of work and social behaviour in order to fit in (Martin, 1980; Young, 
1991; Heidensohn, 1992). A female constable explains that the prominent culture of the police excludes certain kinds of people:

"They only want to know that you are going to work hard. It's all about figures on team. So, as long as you are arresting people, giving out tickets, and going out for drinks; yes, there's a big drinking culture here. I think if you are young and single, you would get on better because there are all these little cliques formed from these activities. So if you have a family, or if you are older and not really into drinking, then you won't be truly part of the team." (Met028 - female, 27, Mixed British)

Research has shown that the coercive nature of police work has led to its members equating policing with physicality (Chan et al., 2003; Fielding and Fielding, 1992; Leishman, Loveday and Savage, 2000). Female officers acknowledged that they were constrained by gendered norms (Davies and Thomas, 2008) and were also treated differently because of their perceived lower physical capabilities. While some saw the need to prove their strength, others simply wanted to find their niche in the organisation. Alvesson and Billing (2009) point out that females who work in a masculine occupation will experience pressure to take on roles that are considered more fitting of their social category. The respondents in this study similarly explained that females who resisted the masculine police archetype would end up taking on policing roles that were typically associated with feminine characteristics. One respondent explained that she had her personal work preferences as a female officer and so had no intention of subscribing to the masculine archetype, which she believed did not suit her personality:

"A lot of people would describe my role as a pink and fluffy role because I deal with children. Females are associated with that role. I'm more attracted to these roles anyhow. The pink and fluffy stuff is the less glamorous side of the business. It seems that the females who are completely opposite to me tend to fit in and go further. The hardened, strong ones would get more results. I always got called up because I wasn't getting all the arrests and figures in. That's not the work I was interested in but that's the work that counts. You have to give as good as they get but I don't like confrontation; I like a fair discussion but in some situations that's not the ideal thing." (Met021, female, 37, White British) 
Researchers argue that police officers exalt violence and uphold a 'cult of masculinity' (Waddington, 1999; Davies and Thomas, 2008) and so the feminine enactment of policing threatens the 'habitus' of police work (Chan 1996). Research in the UK by Westmarland (2001) found that female officers are significantly underrepresented in high profile specialist police departments involving guns, horses and fast cars. This underrepresentation is linked to the gendered division of labour (Connell 2006; Ridgeway and Correll, 2004). An assessment of the job roles carried out by the senior-ranked female officers and managerial level civilian staff in this study supports the notion of gendered division of labour. Listed below are the different managerial roles which nine of the female respondents held in the MPS:

1. Citizen Focus Inspector (customer service);

2. Media \& Communications Manager (office-based);

3. Inspector - Schools and Special Constables (community safety support);

4. Inspector - Response Team (operational);

5. Prosecution manager (office-based);

6. Borough Volunteer Manager (office-based);

7. Strategic HR Adviser (office-based);

8. Inspector - Case Progression Unit (part-time, office-based);

9. Witness care manager (welfare, office-based).

Only one female inspector carried out an operational role at the Inspector rank; all the other female officers occupied stereotypical feminine roles (Brown, 1998; Brown et al., 1993). These officers expressed that they were 'comfortable' in their respective roles, supporting the premise that women generally show a greater liking for feminine jobs (Alvesson and Billing, 2009; Oswald, 2008) such as the safe 'inside' work of customer service and dispute resolution (Martin, 1999). A senior-ranked female detective who works in an office-based managerial role spoke about her experience as a female manager and the importance of maintaining her femininity: 
"Yes, my gender plays a role. I interact with more of the supervisors than with people at the other level of my team. Some of the supervisors have no issues with gender whatsoever and as long as you are good at your job and you support them, there are no issues. And generally, I've got a good track record where that's concerned. Others find it more difficult, and I'm talking about lads [younger male detectives], they find it very difficult to have a female in charge and it's just about how you manage that. I don't feel pressured; some of the girls I started with used to always feel the need to prove themselves. I never felt like that because I always had my role and my niche and I was always quite comfortable with that. As you progress through the ranks you come to realise that it's the way you deal with people and not what you are and everything else. I use my gender to my advantage when I need to. Sometimes you need to develop a good rapport with people and sometimes you cross over to being a bit flirty but it can get you places. As soon as I realised that I could use this to my advantage, I have done but that's in a very general sense. It's very rare for me to get into conflict, sometime I use comedy, sometimes I use feminine charm but I always avoid tensions. If it's a formal situation then I've got the 'corporate bank' which doesn't inflame and is appropriate but if it is informal level it comes back to sort of humour and being me, feminine. I think we communicate better. There are uniform officers that have hated the CID; there have always been a big distinction and officers I've worked with have never got on with them. But I will talk to them despite the rift that exists between CID and uniform officers. Not the same way that I communicate with my team but in general I communicate with them quite easily despite being a detective." (Met051 - female, 39, White British)

This officer identified the benefits of her feminine identity and said that she was comfortable with the idea of working in a role that was seen as appropriate for a female detective. She explained that she was not involved in front-line policing as her job was purely computer-based. This, she said, was quite suitable for her. The female occupation of these office-based, community support, nurturing, "pink and fluffy", and domesticated roles reify the stereotypes of female officers and the reproduction of gender disadvantage (Rabe-Hemp 2009). Ridgeway and Correll (2004) argue that when women enter a particular field and that field is seen to become feminised, it subsequently becomes devalued. Therefore, those who choose to pursue 'appropriate feminine roles' might well be limiting their career prospects because feminine roles are associated with lower performance values or 'recipe knowledge' (Dick and Jankowicz, 2001). 
While some females expressed preference for 'feminine roles' and tried earnestly to resist the pervasive and powerful influence of the masculine police archetype, other female respondents said that it was necessary to assimilate the dominant police identity if you wanted a good career in policing. Women and men are said to be trapped in a vision of masculinity and femininity (Bourdieu, 2001) and so the mythical vision of police work is accepted as being suitable for the 'manly man'. Consequently, women who accept this view will strive to become the 'manly policewoman'. Some female respondents spoke about the masculine demeanour that they exhibited at work in a bid to secure their position on team:

"I am the only female on a team of 30. I think I am one person at work and a different person outside of work. You do feel a need to learn how to 'hang with the boys'. They know they can rely on me, I am trained like everybody else and they've seen me in action. At first, I remember my sergeant being very protective of me. For instance, we go on raids and they would always put me at the back. I didn't like that. I had to show them I could handle the tough stuff like any of the boys." (Met065 - female, 32, White British)

West and Zimmerman (1987) argue that gender is not something we are, but something we do. Therefore, gender is socially reconstructed in light of normative conceptions of gender at work. A female officer who joined the MPS in 1990 explained that females experience more pressure to conform to the masculine structures and processes because gender distinction has been removed from police job titles, roles and uniforms:

"Years ago, we wore skirts, we were called WPCs [woman police constable], had slightly different roles, and special badge numbers but now we wear trousers, carry the same weapons, we are called PC like everyone else, and more and more females are being promoted to senior ranks. Perhaps some females try to be like the guys because there is no longer a gender distinction in titles, uniforms or work roles. The police service is only one part of my job. I don't try to change myself, retaining my feminity is important. There is a stereotype of female officers, but the new crops of females are changing that." (Met001 - female, 38, White British)

The majority of the females were of the view that, although they received both skirts and trousers, they opted to wear trousers because it was more practical for the job. The 
respondents also expressed that the changes in the female uniform and job title signified a move towards gender equality. Still, female officers said that they experienced barriers that were attributable to gender stereotypes. Older female respondents emphasised the importance of eradicating the feminine stereotype so that women would be less influenced to adopt the dominant masculine police identity.

A typical solution for minimising the disadvantage of gender hierarchy in the police service is to 'undo gender' through engaging in social acts that resist gendered norms (Chan et al., 2010; Deutsch 2007). The research shows that some female officers attempt to modify their behaviour according to the masculine nature of police work. However, reducing gender difference or 'undoing gender' is contingent on the social situations in which gendered behaviour or perceptions of gender differences exist. The experience of female officers is therefore, arguably, dependent on the prevailing gender perspectives in the MPS.

While older female officers have acknowledged that being female carried negative symbolic capital (Chan et al., 2010; Deutsch 2007), other younger female respondents said they experienced positive and inclusive attitudes from their teams. They explained that their positive experience was due to the fact that the female officers who previously worked on their teams were seen as competent officers and were respected by the males on the team:

"In terms of my gender, I've never really felt much of a difference. I think that's credit to the other females we had on our team. They had very strong personalities and they were established, competent police officers who were respected on the team. Hence, I didn't feel an instant negative attitude from my male colleagues. I mean, I think everyone finds it difficult on response team because of the nature of the job; you have to rely on your colleagues so much and so opinions are formed very quickly. If one person thinks something of you and that person's views are respected, then potentially that can cascade through the rest of the team." (Met049 - female, 27, Asian British)

The evidence from a range of newer females recruits show that there is a degree of 'positive symbolic capital' for females who have had thriving female predecessors. This was 
not only as a result of females who successfully assimilated the police identity but also those who successfully endorsed an alternative style of policing. Some senior-ranked female officers expressed that their approach to policing was noticeably different from the normal policing approach. One such respondent explained how her ways and means of policing had inspired younger females on her team:

"I did some community policing as a sergeant and I remember a lot of the women feeling empowered that they had a female sergeant in charge of the area. But that was more to do with feeling empowered to do stuff like youth projects or unofficial volunteering. Some of the PCSOs that later joined as a PC said that they were influenced by my way of doing the work. But they wanted to become PCs from the start so I didn't really influence that decision I guess it was more about my ways and means of policing." (Met013 - female, 38, White British)

A male officer spoke about his former female supervisor who he said had a positive influence on his opinion about female officers:

"Yes, I've had a female supervisor. In fact, the best boss I had was female. She was very bright, very able, kind, and made things happen. She was a very good police but still managed to maintain her femininity. She used to go out to buy individual Christmas gifts for her senior management team. She would always get me a book and they were good choices because she knew my interests. She didn't just give me a bottle of whisky; she put thought into choosing her gifts." (Met068, male, 46, Asian British)

The female respondents felt that the presence of influential female officers in the MPS had a positive impact on their integration and success as new recruits. This supports the claims of Ely (1995) that proportional representation of females in the upper echelons of organisations affects gender difference and gender identity at work.

\section{Discussion and Conclusion}

The experiences of most female respondents depicted the gendered division of labour (Davies and Thomas, 2008; Westmarland, 2001) that is linked to the business case, which underpins 
the access-and-legitimacy perspective on diversity (Dass and Parker, 1999; Ely and Thomas, 2001). Organisations that hold an access-and-legitimacy perspective on diversity values diversity as a resource only at the interface between the organisation and its constituents/markets. The lived experiences of female officers illustrate that their gender identity becomes relevant in specific work contexts and so they are able to exert influence mainly in those specific work contexts (similar diversity discourse found in Janssens and Zanoni, 2005).

The empirical evidence has shown that the work systems and processes in the MPS favour the masculine police archetype. Similar strong macho culture and gendered structures and processes have been identified in other research on the police service (Chan et al., 2003; Davies and Thomas, 2008; Dick and Jankowicz, 2001; Doran and Chan, 2003; Leishman, Loveday and Savage, 2000; Martin 1999; Waddington, 1999).

Female officers expressed that they were constrained by gendered norms and were treated differently because of their perceived lower physical capabilities. They were expected to take on work roles that were considered appropriate for female officers (as in Davies and Thomas, 2008; Fielding and Fielding, 1992). Incidentally, as shown above, the senior-ranked female officers in this study all occupied roles that were perceived as "pink and fluffy" officebased, community and school support, or welfare and domesticated roles. Arguably, these 'gendered' roles illustrate constellations of discursive and material controls in the MPS (Zanoni and Janssens, 2007). Female officers are generally confined to the boundaries of femininity but at the same time they are expected to behave like a 'model employee', which involves assimilating the masculine police archetype.

Bourdieu (2001) posits that women and men are trapped in an image of masculinity and femininity and so the mythical vision of police work is accepted as being suitable for the 'manly man'. Female officers challenged the masculine police archetype while they were 
'proving themselves' in order to fit in on their work teams (Martin. 1980; Young, 1991; Heidensohn, 1992). However, once they became established on their team, they expressed their femininity more freely, especially in feminised niches. This perhaps explains why female officers gravitate towards feminine roles once they begin to progress in rank. Other studies have shown that women generally show a greater liking for feminine jobs (Alvesson and Billing, 2009; Martin, 1999; Oswald, 2008). Arguably, the female occupation of these office-based, community support, domesticated, nurturing, and "pink and fluffy" roles reify the stereotypes of female officers and the reproduction of gender disadvantage in career progression (Rabe-Hemp, 2009). A glass ceiling effect could ensue if females continue to pigeon hole themselves by taking on so-called feminised, undervalued roles that lack 'recipe knowledge' of 'real' policing (Dick and Jankowicz, 2001; Davies and Thomas, 2008; Ridgeway and Correll, 2004).

Gerber (2001) posits that men and women only appear to have different personalities because men have higher status than women. This was illustrated in the 'pecking order' that was demonstrated on MPS work teams, which perpetuate a dichotomous and hierarchical construct of gender in policing (Alvesson and Billing 2009). The lack of ascribed status among female officers meant that their achieved status superseded their gender prominence. Dick and Jankowicz (2001) found that membership of a supervisory rank had a significant impact on how female officers were judged in the organisation. The finding from this research show that female officers relied on their rank as a means of exerting influence in the police service, while males typically relied on their reputation as their main source of status and influence. There was only one female respondent who worked as an Inspector on the TSG response team, carrying out a core operational role. This female officer was part of the accelerated promotion scheme for graduates and she pointed out that more attention was paid to her limited experience and tenure, but not her gender per se. 
The experiences of female officers illustrate the problem of stereotyping that is associated with the access-and-legitimacy perspective. The main focus is on using diversity as an asset for external benefits while work systems and processes remain unchanged. Female officers faced pressures of balancing family and work life, further supporting findings from studies that highlight work-related stress among female police officers (Berg et al., 2003; He et al., 2002).

The importance of gender identity in the workplace was also highlighted by females who explained that the presence of female officers in the upper echelons of the MPS had a positive impact on the experience and inclusion of new female recruits. The positive reputation of these existing female officers eliminated, to an extent, what Chan et al. (2010) and Deutsch (2007) described as the 'negative symbolic capital' of new female officers. The analysis provided useful insight on the experience of female officers, identifying the important influence of different work contexts within the complex police occupational culture.

This paper supports the viewpoint that the discourse of diversity is anchored in an organisation's productive logic (Janssens and Zanoni, 2005). The analysis provided useful insight into the experiences of female police officers, identifying the important influence of work context and gender inclusion within the complex occupational culture of the police service. The experiences of female officers illustrated the problem of stereotyping that is associated with the access-and-legitimacy perspective on diversity (Dass and Parker, 1999; Ely and Thomas, 2001) in which the main focus is on using diversity as an asset for external benefits while work systems and processes remain unchanged.

The empirical evidence brought light to the complex intersections of multiple diversity dimensions (McCall, 2005; Holvino 2010), illustrating how female officers had varying experiences of inclusion and isolation, depending on the salience of their multiple 
identity dimensions. Taken separately, gender identity had a strong influence on police officers, but the findings show that other dimensions such as race, age, tenure, sexual orientation, or education mediate the effect of gender identity in the police service. The findings from this study provide a glimpse into the complex interrelatedness of diversity dimensions, and draws attention to the importance of work context in altering the salience of different dimensions of individual identity.

The potential for challenging prejudiced behaviour remains a concern among researchers and practitioners alike. The rigid patterns of police culture indicate that demographic, structural and functional changes are being embedded with its traditional values and practices. This sedimented nature of change therefore poses significant challenges for managing workforce diversity.

This study contributes to the diversity management literature by investigating both above-the-line (organisational policy, strategy and initiatives) as well as below-the-line (employee perspectives on diversity management in the MPS) (Kulik 2014).

\section{References}

Acker, J. 2006. Inequality regimes: gender, class and race in organizations. Gender and Society, 20: 441-464.

Acker, J. 2012. Gendered organizations and intersectionality: problems and possibilities. Equality, Diversity and Inclusion: An International Journal, 31 (3): 214 - 224

Avery, D.R. and McKay, P.F. 2006. Target practice: An organizational impression management approach to attracting minority and female job applicants. Personnel Psychology, 59: 157-187.

Bendl, R., Fleischmann, A. and Walenta, C. 2008. Diversity management discourse meets queer theory. Gender in Management: An International Journal, 23 (6): 382-394.

Beverly, M. and Gavin, D. 2002. Is the force still with her? Gender and commitment in the police. Women in Management Review, 17 (8): 392- 403.

Billing, Y.D. 2011. Are women in management victims of the phantom of the male norm?, Gender, Work and Organization, 18 (3): 298-317. 
Bradley, H., Healy, G. and Mukherjee, N. 2004. Union influence on career development: bringing in gender and ethnicity. Career Development International, 9 (1): 74-88.

Brown, J. 1998. Aspects of Discriminatory Treatment of Women Police Officers in Forces in England and Wales, British Journal of Criminology, 38: 265 - 82.

Brown, J. 2007. From cult of masculinity to smart macho: gender perspectives on police occupational culture, in Sklansky, D.A. (ed.), Police Occupational Culture (Sociology of Crime, Law and Deviance, Vol. 8), Emerald Group Publishing Limited: 205-226.

Chan, J., Devery, C. and Doran, S. 2003. Fair cop: learning the art of policing. Toronto: University of Toronto Press.

Chow, I., Hau, S. and Crawford, R.B. 2004. Gender, ethnic diversity, and career advancement in the workplace: the social identity perspective. SAM Advanced Management Journal, 69 (3): $22-31$.

Colgan, F. and Ledwith, S. 1996. Women as organizational change agents, in Ledwith, S. and Colgan, F. (eds.). Women and Organisations: Challenging Gender Politics. London: Macmillan: 1-43.

Connell, R. 2006. Glass ceilings or gendered institutions? Mapping the gender regimes of public sector worksites. Public Administration Review, 66 (6): 837-849.

Connell, R. 2009. Accountable conduct: doing gender in transsexual and political retrospect. Gender \& Society, 23 (1): 104-111.

Cordero, R., DiTomaso, N. and Farris, G. F. 1997. Gender and race/ethnic composition of technical work groups: relationship to creative productivity and morale. Journal of Engineering and Technology Management 13: 205-221.

Dass, P. and Parker, B. 1999. Strategies for managing human resource diversity: from resistance to learning. The Academy of Management Executive, 13 (2): 68-80.

Davies, A. and Thomas, R. 2008. Dixon of dock green got shot! Policing identity work and organizational change. Public Administration, 86 (3): 627-642.

Deutsch, F.M. (2007). Undoing Gender. Gender \& Society, 21 (1): 106-127.

Dick, P. and Jankowicz, D. 2001. A social constructionist account of police culture and its influence on the representation and progression of female officers: a repertory grid analysis in a UK police force. Policing: An International Journal of Police Strategies \& Management, 24 (2): 181-199.

Doran, S. and Chan, J. 2003. Doing gender, in Chan, J. with Devery, C. and Doran, S., Fair Cop: Learning the Art of Policing. Toronto: University of Toronto Press: 276-300.

Duffy, M. 2004. Reproducing labor inequalities: challenges for feminists conceptualizing care at the intersections of gender, race, and class. Gender and Society, 19: 66-82. 
Dwyer, S., Richard, O.C. and Chadwick, K. 2001. Gender diversity in management and firm performance: the influence of growth orientation and organizational culture. Journal of Business Research, 56 (12): 1009-1019.

Ehrich, L.C. 2008. Mentoring and women managers: another look at the field. Gender in Management: An International Journal, 23 (7):469 - 483.

Ely, R. 1995. The power in demography: women's social construction of gender identity at work. Academy of Management Journal, 38 (3): 589-634.

Ely, R.J. and Thomas, D.A. 2001. Cultural diversity at work: The effects of diversity perspectives on work group processes and outcomes. Administrative Science Quarterly, 46 (2): 229-273.

Fielding, N. 1994. Cop canteen culture, in Newburn, T. and Stanko, E.A. (eds.), Just Boys Doing Business: Men, Masculinities and Crime. London: Routledge.

Gerber, G.L. 2001. Women and men police officers: status, gender, and personality. Greenwood Press.

Harvey, A.M. 2005. Becoming entrepreneurs: intersections of race, class, and gender at the black beauty salon. Gender and Society, 19, pp. 789-808.

He, N.; Zhao, J. and Archbold, C.A. 2002. Gender and police stress: The convergent and divergent impact of work environment, work-family conflict, and stress coping mechanisms of female and male police officers. Policing, 25: 687-707.

Holvino, E. 2010. Intersections: the simultaneity of race, gender and class in organization studies. Gender, Work \& Organization, 17 (3): 248-277.

Holvino, Evangelina 2010. Intersections: The Simultaneity of Race, Gender and Class in Organization Studies. Gender, Work \& Organization, 17 (3), 248-277.

Heidensohn, F. 1992. Women in Control: The Role of Women in Law Enforcement. Oxford: Oxford University Press.

Iles, P., Wilson, E. and Hicks-Clarke, D. 1998. Diversity climates and gendered cultures: a cross sector analysis, in C. Mabey, D. Skinner and T. Clark (eds), Experiencing Human Resource Management, London: Sage.

Itzin, C. 1995a. Crafting strategy to create women-friendly work, in Itzin, C. and Newman, J. (eds.), Gender, Culture and Organizational Change: Putting Theory into Practice. London, New York: Routledge: 127-151.

Itzin, C. 1995b. Gender, culture, power and change: a materialist analysis, in Itzini C. and Newman, J. (eds.), Gender, Culture and Organizational Change: Putting Theory into Practice, London, New York: Routledge: 246-272. 
Janssens, M. and Zanoni, P. 2005. Many Diversities for Many Services: Theorizing Diversity (Management) in Service Companies. Human Relations, 58(3): 311-40.

Joshi, A. and Roh, H. 2009. The Role of context in work team diversity research: a metaanalytic review. Academy of Management Journal, 52 (3): 599-627.

Knapp, G. 2005. Race, class, gender: reclaiming baggage in fast traveling theories. European Journal of Women's Studies, 12: 249-265.

Kulik, C. T. 2014. Working Below and Above the Line: The Research-Practice Gap in Diversity Management. Human Resource Management Journal, 24: 129-144.

Leishman, F., Loveday, B. and Savage, S. 2000. Core issues in policing. Pearson: England.

Litvin, D.R. 1997. The discourse of diversity: From biology to management. Organization, 4(2): 187-209.

Martin, P.Y. and Collinson, D. 2002. Over the pond and across the water:' developing the field of 'gendered' organizations. Gender, Work \& Organization, 9 (3):244-65.

Martin, S.E. 1980. Breaking and entering: policewomen on patrol. Berkeley, CA: University of California Press.

Martin, S.E. 1999. Police force or police service? Gender and emotional labor. The Annals of the American Academy of Political and Social Science, 561 (1): 111-126.

Martin, S.E. and Jurik, N.C. 2006. Doing justice, doing gender: women in legal and criminal justice occupations. Los Angeles, CA: Sage.

Maxwell, G.A., Blair, S., and McDougall, M. 2001. Edging towards managing diversity in practice. Employee Relations, 23 (5): 468-482.

Moore, D. 1999. Gender traits and identities in a "masculine" organization: the Israeli police force. Journal of Social Psychology, 139 (1): 49-68.

Monserrat et al. 2009. Mentoring experiences of successful women across the Americas, Gender in Management: An International Journal, 24 (6): 455 - 476.

Mor Barak, E.M. 2000. The inclusive workplace: an ecosystems approach to diversity management. Social Work, 45 (4): 339-352.

Mor Barak, M.E. 2005. Managing Diversity: Toward A Globally Inclusive Workplace. London: SAGE Publications.

Mor Barak, M.E., Cherin, D.A. and Berkman, S. 1998. Organizational and Personal Dimensions in Diversity Climate: Ethnic and Gender Differences in Employee Perceptions. The Journal of Applied Behavioral Science, 34: 82-104.

Rabe-Hemp, C. 2009. 'POLICEwomen or PoliceWOMEN? Doing Gender and Police Work. Feminist Criminology, 4 (2): 114-129. 
Silvestri, M. 2003. Women in Charge: Policing, Gender and Leadership. Willan:

Cullompton.

Smith, D. J. and Gray, J. 1985. Police and People in London: The PSI Report. London: Policy Studies Institute.

Steinbugler, A.C., Press, J.E. and Dias, J.J. 2006. Gender, race, and affirmative action: operationalizing intersectionality in survey research. Gender and Society, 20: 805-825.

Tatli, A., Ozbilgin, M. and Ktiskil, F. 2008. Gendered occupational outcomes: the case of professional training and work in Turkey, in Eccles, J. and Watt, H. (eds.), Explaining Gendered Occupational Outcomes. Michigan: American Psychological Association Press.

Thomas, R.R. 1991. Beyond race and gender. New York: AMACOM.

Tonge, J. 2008. Barriers to networking for women in a UK professional service. Gender in Management: An International Journal, 23 (7): 484 - 505.

Truss, C. 1999. Human resource management: gendered terrain? The International Journal of Human Resource Management, 10 (2): 180-200.

Waddington, P.A.J. 1999. Police (canteen) sub-culture: an appreciation. British Journal of Criminology, 39 (2): 287-309.

Walklate, S. 2000. Equal opportunities and the future of policing, in: Leishman, F., Loveday, B. and Savage, S. (eds.) Core Issues in Policing, (2nd edition). Essex: Pearson Education Ltd.

Ward, J. 2004. Not all differences are created equal: multiple jeopardy in a gendered organization. Gender \& Society, 18(1): 82-102.

Warren, C. 1988. Gender issues in field research. London: Sage Publications.

West, C. and Zimmerman, D.H. 1987. Doing Gender. Gender \& Society, 1 (2): 125-151.

West, C. and Zimmerman, D.H. 2002. Doing Gender, in West, C. and Fenstermaker, S. (eds.), Doing Gender, Doing Difference: Inequality Power and Institutional Change. New York: Routledge: 3-24.

West, C. and Zimmerman, D.H. 2009. Accounting for doing gender. Gender \& Society, 23 (1): 112-122.

Westmarland, L. 2001. Gender and policing: sex, power and police culture. Cullompton: Willan.

Yuval-Davis, Nira 2005. Gender mainstreaming and intersectionality, Swedish Journal of Women's Studies (Kvino-vetenskaplig tidskrift), special issue on 'Inter- sectionality' 2-3, 19 29. 
Yuval-Davis, Nira. 1997. Women, Ethnicity and Empowerment: Towards Transversal Politics, in: Nira Yuval-Davis (ed.), Gender \& Nation. London: Sage.

Zanoni, P. and Janssens, M. 2003. Deconstructing difference: the rhetoric of human resource managers' diversity discourses. Organisation Studies, 25 (1): 55-74.

Zanoni, P. and Janssens, M. 2007. Minority Employees Engaging with (Diversity) Management: An Analysis of Control, Agency, and Micro-Emancipation. Journal of Management Studies, 44: 1371-1397. 